\title{
Vigilância em Saúde na Zona da Mata Mineira: satisfação profissional em foco
}

\author{
Cíntia Pereira Donateli, Patrícia Silva Avelar, Ariadne Barbosa do Nascimento Einloft, Tania Segura \\ Quesada, Glauce Dias da Costa, Rosangela Minardi Mitre Cotta
}

\section{Resumo}

Definida como estado emocional agradável ou positivo, a satisfação no trabalho resulta do alcance de valores compatíveis com as necessidades profissionais. Reconhecendo-se que a atividade laboral repercute tanto na sua saúde física quanto mental e que um dos indicadores de qualidade dos serviços de saúde é o nível de satisfação dos profissionais que neles atuam, o monitoramento destes indicadores pode auxiliar em diagnósticos para subsidiar decisões que atendam às necessidades e possibilidades locais. Identificar a satisfação profissional dos coordenadores municipais das Vigilâncias Ambiental, Epidemiológica e Sanitária de sete municípios polo de saúde da Zona da Mata Mineira. Este estudo avaliativo de abordagem quanti-qualitativa foi realizado nos sete municípios polo de saúde da Zona da Mata mineira (Cataguases, Juiz de Fora, Manhuaçu, Muriaé, Ponte Nova, Viçosa e Ubá) e faz parte da pesquisa intitulada "Avaliação das práticas de prevenção das doenças e promoção da saúde na Zona da Mata Mineira" que visa avaliar as atividades da Vigilância em Saúde local. A coleta de dados ocorreu no segundo bimestre de 2016 e consistiu na aplicação aos coordenadores das Vigilâncias Epidemiológica, Ambiental e Sanitária de um questionário semiestruturado elaborado segundo a tríade Estrutura/Processo/Resultado de Donabedian. Destaca-se que esta etapa da pesquisa possui um recorte para a atuação dos gestores, com ênfase na satisfação profissional, visto que esta é um dos pilares do bom funcionamento dos serviços de saúde, podendo refletir em vários pontos da organização. Respeitando os aspectos éticos e conforme a Resolução n ${ }^{\circ}$ 466/12 do Conselho Nacional de Saúde, foi submetido ao Comitê de Ética em Pesquisa com Seres Humanos da Universidade Federal de Viçosa, sendo aprovado com parecer $n^{\circ} 1447272$. Foram entrevistados 21 profissionais da Secretaria de Saúde dos municípios pesquisados e que atuavam como coordenadores das Vigilâncias ambiental, epidemiológica ou sanitária. Quase a totalidade $(95,2 \%)$ acredita na função que executa. No que tange à competência específica para exercer o cargo, 57,1\% dos coordenadores disseram estar aptos para tal e 76,2\% afirmaram não haver distanciamento entre a formação e a atuação na prática. Quanto à satisfação com o desempenho das atividades rotineiras, 90,5\% dos entrevistados disseram se sentirem satisfeitos, entretanto, o excesso de responsabilidades $(57,1 \%)$ e o trabalho burocrático $(57,1 \%)$ foram citados como condições que interferem no desenvolvimento destas e que acabam levando ao acúmulo de tarefas variadas $(90,5 \%)$, com destaque para a Vigilância Sanitária na qual todos os entrevistados ressaltaram essa demanda aumentada. Apesar de 76,2\% dos informantes relatarem que não recebem salário apropriado para o cargo e que 57,1\% não possuem liberdade para apresentar críticas, $71,4 \%$ afirmam se sentirem valorizados profissionalmente. A análise da satisfação dos coordenadores das vigilâncias permitiu perceber a existência de potencialidades como autovalorização, satisfatória experiência profissional e desempenho adequado favorável à resolubilidade de sua área de atuação. Entretanto, a existência da sobrecarga de trabalho e a remuneração inadequada, podem favorecer fatores de estresse presentes na dinâmica de trabalho e prejudicar o desenvolvimento de novas práticas profissionais que possibilitem a reestruturação do modelo de Vigilância em Saúde.

Descritores: Vigilância em saúde; Serviços de saúde; Satisfação profissional 